\title{
Space and embodiment in informal learning
}

\author{
Andrew M. Cox ${ }^{1}$ \\ Published online: 2 September 2017 \\ (C) The Author(s) 2017. This article is an open access publication
}

\begin{abstract}
Changes in pedagogy to emphasise independent study and group work have increased the need for informal learning spaces on campuses. University libraries have been quick to respond to this need, partly because of the decline in book lending and partly because of technology enablers. Furthermore, new types of buildings that combine many types of facility, including libraries and informal learning spaces, are being built. This research aimed to explore students' experience of such informal learning spaces, through focus groups and walk with interviews. It was found that the creation of different types of learning atmosphere, should be understood as a multi-sensory experience, and actively constructed by learners themselves. Informal learning spaces are important destinations for students, who have favourite places to study, where they often work alongside companions and find motivation to work in the presence of others.
\end{abstract}

Keywords Informal learning $\cdot$ Learning spaces $\cdot$ Libraries $\cdot$ Embodiment

\section{Introduction}

A number of commentators have noted that despite the huge investment made by universities in campus buildings, there has been a persistent failure to study and theorise space and place in Higher Education (Temple 2008; Ellis and Goodyear 2016). In contrast to this relative neglect, the professional literature of librarians contains a growing corpus of work on reimagining the library as a place for "informal learning". Inspired by Scott Bennett's (2005, 2006, 2011) writing about the "learning commons", librarians have discovered a new role for the library as a resource-rich environment in which different forms of learning are undertaken. A number of studies have looked at what students' value in such redesigned library spaces.

In the light of changing pedagogic practices which stress independent and social learning, we could reconceptualise the whole campus as a learning landscape (Dugdale 2009). Across this landscape, a wide range of activities from seeking information, reading, group work,

Andrew M. Cox

a.m.cox@sheffield.ac.uk

1 The Information School, University of Sheffield, Regent Court, 211 Portobello, Sheffield S1 4DP, UK 
assignment preparation to intense revision take place. Such informal learning is defined by Matthews et al. $(2011,107)$ as "student learning outside of designated class time" or by Jamieson (2009) as "course-related activity undertaken individually and collaboratively on campus that occurs outside the classroom and does not directly involve the classroom teacher." Libraries and library-like spaces have to be recognised as an important part of the landscape for such activities. It is here, as much as in lecture rooms or seminars, that students learn. The design of libraries has long since shifted away from places to store books towards places to learn. And as many campus buildings are redeveloped to support informal learning, lessons learned by libraries become of even wider relevance. It is therefore important to explore how students themselves use and experience different sorts of informal learning space and how this fits into learning in Higher Education.

A focus on the spaces within which students learn may also open up an interesting perspective on the role of the body in learning. The material and social surroundings of the student has an impact on their experience of study, and is strongly linked to bodily routines and activities (Hopwood and Paulson 2012). Recognition of the importance of embodiment in learning has gained ground in the learning of skills (O'Connor 2007) and arts and sports (Bresler 2013). A focus on spaces of learning has the potential to reveal more about the role of the body in learning throughout the curriculum. After all, such basic learning tasks as writing (Clughen 2014) and reading (Mangen 2014; McLaughlin 2015) are in significant ways embodied. Bodily characteristics and states affect learning. Learning is experienced as an embodied, not just a cognitive (and emotional), process. This applies not just to learning physical skills. The thoughts we have when walking are different from those we have when sitting; hence, many authors have found walking stimulates creativity (Clughen 2014). How we read text on a tablet differs from how we read a traditional book, partly because of the physical differences (Mangen 2014). The experiences of the senses are culturally shaped. It follows that the physical characteristics of the places where learning happens may influence learning as a process.

In this context, the aim of the study reported in this paper was to investigate student experience of informal learning spaces. The paper is organised as follows. The context for librarians' interest in informal learning is explained, and the writing of a key author, Scott Bennett, on social learning is contrasted with arguments for the continued value of quiet, communal space. Conclusions from studies that explore how students use and experience library space are reviewed. The method for the current study which was focus groups and walk with interviews in a UK university is then explained. Findings are organised around two main themes: the sensory landscape of informal learning and the pattern of students settling in a favourite spot in the library. The paper closes with a discussion of informal learning spaces as destinations. The contribution of the study is to increase our understanding of student experience of spaces for informal learning and to begin to explore how a learning atmosphere is constituted as a sensory experience.

\section{Libraries and learning}

During this century there has been a growing interest in the professional world of academic libraries in social and informal learning spaces. Some commentators locate this interest firmly in the search for a role for the library and specifically library spaces, arising from the decline of book borrowing and the shift to electronic content (e.g. Ojennus and Watts 2015). Numerous 
studies seem to be showing a decline in library use. Thus, in terms of professional status, interest in informal learning aligns with a shift in librarianship from the threatened access jurisdiction (the authority of the librarian based on their management of a book collection) to an educational jurisdiction (O'Connor 2009). Rather than simply training students to use the library (user education) teaching users to understand how to gather and use information effectively, to be "information literate" has become a central professional concern. The increasing interest in what students actually do in the library and how this relates to learning aligns with this turn towards an interest in learning in the profession. More positively, one could say that greater resource-based learning has been enabled and shaped partly by a context of information abundance, offered by the internet, but critically also through library-provided electronic subscriptions. This has worked in tandem with other technological trends such as wifi and a computing philosophy of bring-your-own device to free up space previously occupied by ranks of computers and book shelves, and so making it possible to create new types of learning space.

These are effectively "supply side" shifts. Other authors in the library literature have located the need to alter how library space is used in the context of the changing needs of learners, specifically the notion that a new generation of "millennials" with different learning styles and expectations (e.g. Yoo-Lee et al. 2013). Some of the changes attributed to this particular generation should perhaps be better seen as reflecting longer term changes in how people wish to learn.

Authors such as Jamieson $(2009,2013)$ place changes in use of library space firmly in the context of shifts of pedagogic theory among educators. As theories of learning have moved away from an instructivist model to emphasise the value of independent, active learning and particularly social learning, so this has been translated in spatial use to a decentring of the lecture theatre in favour of seminar space, but also spaces for group learning and other informal learning (Jamieson 2013). In the UK, another very important factor in changing use of space has been a boom in building driven by competition for students. Building better facilities for students has reflected the drive to increase student numbers, especially international students. Providing excellent spaces for students reflects their growing status. Such competition for students has continued through the economic recession since 2008. Institutional policy has made high-quality students experience a major objective; and space is recognised to contribute significantly to this. Libraries are increasingly asked to demonstrate their direct impact on core institutional purposes such as student learning and engagement.

\section{The "learning commons" and the communal library}

For librarians rethinking library space in response to these pressures and opportunities, the work of Scott Bennett $(2005,2006,2011)$ and the concept of the "learning commons" has been a key influence. Bennett (2005) seeks to understand how to create a "powerful learning environment... achieved as a function of the building itself creating a community for learning." He observes that the places where students discuss course ideas outside class tend to be domestic spaces such as student halls or dining rooms. He argues that these spaces do not privilege the lecturer or the librarian, like the lecture theatre or the traditional library, but have a communal feel (Bennett 2005). This prompts him to call for the "domestication" of library space (Bennett 2005). Domestication implies certain principles for how space is organised, such as that it should be a place where "one knows something of the others who use the space; 
little is alien to the community that uses it; there are few threats to one's ability to be oneself, to grow and to learn; activities are often spontaneous and responsive to the learning tasks at hand; the occupants identities and activities are celebrated" (Bennett 2005). Bennett (2006) identifies other principles for successful learning spaces: that they support a distinction between socialising and studying; provide choice and flexible uses; allow for territorial claims; and foster a sense of community. Given his professional focus, he concentrates on what librarians who design and manage space can do, and gives less consideration to the active agency of students themselves in creating appropriate spaces. Yet Bennett's conceptualisation of the learning commons is firmly rooted in the idea that rather than information consumers, library users are learners and that learning is social. For Bennett, the move to a focus on learning aligns the library better with institutional purposes. Studies of student engagement are a common reference point, showing his concern to consider the library's contribution to key metrics of institutional success.

Bennett's work does recognise the need for students to have seclusion and control distraction (Bennett 2005) and he also perceives the range of activities that reflect engagement with learning (Bennett 2011). Nevertheless, it is evident that his work emphasises the need to support the social element of learning, to the exclusion of the needs of other tasks, such as reading or exam preparation. Gayton (2008) has been widely cited in the library literature for his challenge to the concept of the "learning commons" if it means that the library becomes too busy and noisy. "Communal activity in academic libraries is a solitary activity: studious, contemplative and quiet", he writes (Gayton 2008, 60 ). In this model, the presence of others is important to study, but less through interaction, more through co-presence and as a source of inspiration to study. Noise in the library is a critical issue, it would seem. Historically, in the public library, the production of silence can be seen as enforcing civility; it is an act of social power (Mattern 2007). This is probably part of why the image of the shushing librarian is a professional embarrassment. Nevertheless, there is a large professional literature on how to manage noise in libraries such as by zoning, furniture choices, signage and policy (Yelinek and Bressler 2013). Social norms and expectations also play an important part. Sequeiros (2011) has shown how a "reading atmosphere" in the public library is actively created by users themselves. Particular regimes of noise seem to be associated with libraries and study, yet little has been done to explore this same process in an academic context.

An inspiration for such work could be sensory studies, the study of the cultural construction of meaning attached to the different senses. This is often rooted in sensory anthropology and the history of the senses (Howes and Classen 2013), but a more sociological account has been developed by Vannini et al. (2012). The authors use the term "somatic work" to recognise the active way we construct meaning through the senses. In this perspective, the senses are recognised to be learned skills. They are also a locus of power: A key thesis in sensory studies is that there is hierarchy, a sensory order, in how the senses are viewed in particular cultures and that the privileging of sight (ocularcentrism) is a particular trait of western culture.

\section{Student use of learning spaces}

Within the context of the conceptual debate about the learning commons, an increasing number of empirical studies have sought to capture how students actually use library space (e.g. Harrop and Turpin 2013; May and Swabey 2015; Ojennus and Watts 2015), particularly 
newly designed areas for collaborative work (Bryant et al. 2009; Matthews et al. 2011; Crook and Mitchell 2012) and what underpins student preferences as a whole (Yoo-Lee et al. 2013).

Although based on a study of a single library, a paper by May and Swabey (2015) is suggestive of some important features of use of learning space. Firstly, the authors find that the library is an important destination, with students often setting off to study there for an extended period. Potentially rendered increasingly obsolete by the decline of the printed book, as a place to study, the library regains its status as a central location on campus. Significantly, the library here is not merely for accessing information and a significant proportion of users have a sense of belonging to the library (see also Harrop and Turpin 2013). May and Swabey find that when they are in learning spaces, students do lots of different types of things (see also Yoo-Lee et al. 2013; Ojennus and Watts 2015). This includes everything from quiet independent study through to group work, to simply socialising (offline and online) as a break. In this sense, the term of informal learning is a rather vague catchall term. Eating and drinking is a common activity in libraries (Yoo-lee et al. 2013) - echoing themes in Bennett's domestication agenda. While the list of things students do in the library includes reading for pleasure and sleeping, these tend to be less common than the various study-related tasks. Thus, libraries are used for a wide range of activities, but seem to be successful in avoiding becoming simply another social space, so "supporting a distinction between studying and socializing that does not deny the social dimension of study", as Bennett (2005) puts it. Of course, each of these types of activity can have their own spatial needs (in terms of space, quiet, resources etc) and this may explain the somewhat contradictory results for student preferences found in research (May and Swabey 2015). Harrop and Turpin (2013), for example, find both a desire for "conversations" and "community" but also for "retreat". The findings suggest that in a sense both Bennett and Gayton are right.

May and Swabey identify that a majority of respondents in their study had a favourite place or places in the library, defined by factors such as isolation, space to spread out, being near resources, being near a window and having a power supply. Features of spaces such as the amount of room, noise level, degree of crowding and comfort of furnishing are major factors for students (Cha and Kim 2015). IT resources can be an important factor in choice of space (eg Harrop and Turpin 2013) but expert support from library staff does not appear to be a major influence (Yoo-Lee et al. 2013).

\section{Methods}

Such studies driven by the search to improve the design, furnishing and management of new types of learning spaces, and an interest to discover how students really use them, have prompted researchers to innovate in the range of data collection methods they use. Methods such as interviews and surveys are still employed (Bennett 2011; May and Swabey 2015; Yoolee et al. 2013), but it is has pushed researchers to employ more novel, creative and participatory methods: especially observation, log books and ethnographic methods (Bryant et al. 2009; Crook and Mitchell 2012; May and Swabey 2015; Hunter and Cox 2014) but also visual and mapping methods (Cox 2011; Harrop and Turpin 2013). This reflects a move from a model of measuring student satisfaction, to a more open-ended need to explore the experience of learning that calls for richer qualitative data.

The study reported here aligns with a recognition of the need for this kind of research to draw out students' own perceptions through interpretative methodologies. Interviews with five 
members of library staff explored the perspective of those monitoring and managing the use of space, including people involved in the original design of the Diamond. Focus groups, with a total of 21 participants, were organised with students in four social science departments (Journalism, Education, Economics and Sociology). This allowed us to explore for potential for differing experience across disciplines, as well as factors such as the influence of the location and facilities of the home department. In parallel, to bring out the richness of individual experience, we also conducted "walk with interviews" with 11 students (from the Information and Management Schools). Walk with interviews are a type of go along interview, where the interviewer accompanies the interviewee on a walk through a physical and social environment, and asks them to talk about their associations and experiences with that space. Kusenbach (2003) proposed the method as a variation on ethnographic participant observation. Akin to the participatory walking interview used by Clark and Emmel (2010), they fit into a widening range of walking based interview types (Evans and Jones 2011) and sensory methods (Pink 2015). The method has not to the author's knowledge been used in studies of informal learning to date, and only Holton and Riley (2014) seem to have used it before in the educational context.

The method seems a natural one to employ in a study of learning spaces. In general, it has a number of merits and weaknesses (Dubé et al. 2014; Carpiano 2009; Jones et al. 2008). One benefit of the method is that it inherently demonstrates an interest in the participants' perspective and builds rapport. The approach helps uncover more indepth everyday experience and is likely to elicit non-rehearsed responses. During the walk, serendipitous encounters and being in the places that are being discussed spark relevant trains of thought and memories. However, those who have used the method recognise that there might also be some challenges with it. Several such issues, such as around safety and the interference of the weather with walking, did not apply in our context. There are also some risks around confidentiality, at least if the walk is being openly recorded. In this case, we relied on very detailed note taking, and writing up a very full account of the walk immediately afterwards.

Participants in the study were students at all levels of study drawn from a number of social science departments. The research was approved by the University's ethics process. Data was analysed thematically, with some codes and themes arising from the literature, others more grounded in the data.

\section{Case study context}

The study was undertaken at the University of Sheffield, a British research intensive university founded at the beginning of the C20th. It has more than 27,000 students and 1500 academic staff organised in 56 departments grouped in faculties of Arts, Engineering, Medicine, Sciences, and Social Sciences. Students have a rich range of places to study. The original main library, now called Western Bank Library, is a modernist building opened in 1959, by T.S. Eliot. It houses the main book stock, and could be seen as a classic research library. Sheffield's Information Commons (IC), opened in 2007, was one of the first new types of learning centres that combined a collection of in-demand texts and computing facilities, and is open 24/7 (Lewis 2010). A further extension to this model, The Diamond, was opened in 2015 at a cost of $£ 81$ million. It is home to the engineering faculty and has specialist teaching facilities and 19 laboratories such as a chemical engineering pilot plant, an aerospace 
simulation lab and a virtual reality suite. Glass walls enable those working in the building to see what is going on in the labs. The Diamond also has a 24/7 library, IT services and open learning spaces made available to students from all departments. A fly through of the building is available from University of Sheffield (2017). Billed as the "Information Commons" in the Diamond, it was seen as a further development of the IC's philosophy of "student-led learning". This is a classic instance of how multiple types of space are appearing across the campus as learning landscape.

\section{Findings: the sensory experience of informal learning}

Participants had a strong feel for the sensory possibilities of the available informal learning spaces around the whole campus. While none of the elements they talked about were a surprise in itself, what was revealed (partly by the walk with method) was an awareness of these study places as a rich and diverse sensory landscape.

Very specific regimes of light and visibility seemed to be desired. Light was important, especially natural light. The usual reason given was that it was aesthetically pleasing and gave one a connection to the time of day-rather than it was better for reading.

What I like about the Diamond is how it brings in the outside, the large windows... it proves that it makes people feel more happy, being in touch with the outside rather than being in a secluded room with four walls and no windows, so I think that is what I really like about the Diamond is that it invites the outside in and I think it does increase my focus."

"When I study here it is more productive than when I study in my room. The light is not yellow. It is appropriate to study.

In some buildings the light at night was poor. Participants had learned quite subtle differences between different places:

The light can be quite aggressive in the Diamond... Natural light is good, sometimes it can be really overbearing white light and it is just a bit like dazzled.... Western Bank is an interesting point because like the reading room in the Western Bank, in the day time there is a lot of natural light that comes in from the window which is great, but at night the light is really like dismal, artificial, yellowy light and in the basement there is no indication whether it is two in the morning or two in the afternoon. So I think natural light is good, and sort of a soft but not overpowering light.

Windows let in light but also offered views. As other research has suggested, views have some importance (Cha and Kim, 2015). A view outside helped relieve the sense of pressure and claustrophobia; and was also an inspiration.

I can see outside and do not feel suffocated. I can daydream."

"I prefer to sit at the window end, because sometimes if I am so tired, you can just turn around and look outside. It feels much better.

But some felt it was a distraction to see things outside. The view inside was also important.

One of the most important attractions of the informal learning spaces was that there were other people working there. Seeing others working helped students concentrate on work themselves: so the view inside was possibly more important than the view outside. 
I like the pressure of the silent study room. I like that when you take your phone out, you feel like everyone is watching you, I like that pressure.

A number of participants mentioned liking to see others working in different types of way.

Yet many students liked a degree of privacy. Favourite places often were a little secluded. The IC and Diamond were sometimes seen as too "open".

In a corner and there is nobody behind me."

"If I am on my own, I have got to be anonymous.

Thus, paradoxically, students liked to be know others were working around them, yet not to be distracted too much by seeing them and also not be overlooked by others: to have a little privacy within a public area. Hence working spaces with some enclosure were popular.

The grey booths are kind of like a horse with blinders on, you cannot see others and it is silent.

Some people felt a sense of anonymity from being in a space with people working in many types of way; others felt they wanted to be actually less visible.

Thus participants had quite specific desires about what they should see and whether they could be seen. They were also very sensitive to a very particular sound landscape. There were many references to different types of quiet in the data, reminding us of the importance of noise, echoing the centrality of this in the professional literature of librarians.

Designated "silent space" is where there is no talking, but there could be lots of little irritating noises, such as eating or the sound of typing.

That I cannot stand, I hate that in a library. Especially in the IC in the silent study [...] I think it is people eating like a bag of crisps... and then there is the smell that creates, I do not think that that creates a good environment to work.

One focus group participant said that when revising, he needed it to be completely quiet. IC silent areas were not really silent he said: "I don't want to be distracted by even rustling of papers [and] people noises". Instead he went to Western Bank library because the stacks there were "dead silent... it is like a dungeon." Other participants felt that the need to be silent in Western Bank was intimidating or oppressive.

Another thought the IC was like a "doctor's waiting room. The only thing you hear in there is a faint cough in the distance". This was good for revision, but at other times he wanted background music, so studied at home. Thus particular tasks called for the creation of particular sensory environments.

Another participant talked about the pressure cooker atmosphere in a quiet area in the IC. This seemed much more intense because the room was open, you could see others working with very serious expressions. This created a highly charged silence of intense concentration. In other spaces, there was a little more freedom to do different things, because one was oneself invisible.

Thus particular orders of sound, as well as visuality, and light seemed to be important to how spaces were experienced in relation to informal learning.

Here, the learning atmosphere is a multi-sensory experience; it also had a strong emotional content. Other comments in the interviews and focus groups related to temperature, air quality, cleanliness and décor as impacting how one learned. One person responded to the colour coded decoration of different floors. "The colour is very bright and it make me happy. But when you go to the $3^{\text {rd }}$ floor its blue, I do not like that much." 


\section{Settling in a favourite spot in the library}

The libraries and learning spaces like the Diamond on the University of Sheffield campus were very important destinations for students. They might drop-in between lectures, but they also often set off intentionally to spend a long time studying there, sometimes in overnight sessions. This required careful preparation: arranging a time with friends; booking rooms or computers; and bringing books and food. As well as there being more resources in these learning spaces, a major factor in choosing where to study was that students wanted to work alongside other students they knew. This related less to group work, than simply having companionship and a sense of support from others facing the same learning challenge. One interviewee commented: "It felt more like gathering and less like studying". If she had any questions, she could ask her friends. They would order a pizza and sit in the café and eat together. "It felt like we were in it together".

Within the learning spaces, students tended to have one or a few specific favourite places to work. There was a sense of ownership in these places. Some participants gave names to them like "the spot" described below:

Having tried different places, I found "the spot". It was in a corner, close to a window, so it was naturally light. It was a big table with a computer and I could easily place my laptop and books next to me. Also, it had a desk light which allowed me to turn off and on. A few times during breaks, I turned the light off to rest my eyes from having looked at the monitor for so long. If I was unable to turn the light off, I would have been forced to move away from the table and rest elsewhere. I liked to see other students working. I could see some students working individually, in a group, using the computer, personal laptops, sitting at the table, on comfy chairs, sitting on the floor between book shelves. The spot was close to book shelves and it had a library touch. I felt I could see others easily, yet I could not be seen so much.

Although places like libraries and the Diamond are very carefully planned landscapes, students experience them freshly through the senses and attach meaning (and their own names) to them. Choosing places where what they could see and hear and how they could be seen and heard was crucial to such preferences. So too were the social qualities of different spaces.

As a result of having favourite spaces others knew where to find them.

It is nice to know that someone on your course is somewhere. Usually me and my mates are sort of at three of four locations in the Diamond that we all know where each other is just to ask questions.

Students often worked alongside each other and groups regularly used particular areas. Friends often set off to the library together. The presence of friends allowed one to take a break, without leaving one's possessions unwatched. Sitting away from the usual space was a signal they did not want to be disturbed on that occasion. It was common to leave belongings behind to claim a space; and also to claim space for friends before they arrived. Although this also created problems in terms of "hogging" places, this behaviour could be a key to the community or domestic feel. Certainly choosing the social character of the space one was in, being close to others one knew and people like oneself who were studying was key to students' active creation of a "domesticated" atmosphere for study.

Underlying this was a sense that university spaces felt safe. People rarely worked outside them, except at home. Yet home was seen as too full of distractions and prompts to 
procrastinate. They did not mention going to places outside the university, even though Sheffield is a city campus. Students saw a library as signalled by book shelves and associated it with working quietly. Given the variety of learning spaces offered on campus, the "library feel" was relative. A place could be "quite library" or "very library".

One group of students (Journalism students) felt their home Department was their home space. But most students in the study seemed to find a preferred space in a library or in the Diamond, working alongside others and this was like a home base. Even the $\mathrm{PhD}$ students in the Information School who had their own spaces in the School used the library spaces a lot. Most students were aware of many of the different types of library space and had explored them.

Students often wanted quite a lot of room to spread out. This might be simply for their belongings. One liked the first floor of the Diamond because:

I can take as many chairs as I need. I usually take four chairs, one for me to sit and three

to put my things, my books, my modules and two bags.

There were negative comments on places where there was not room to spread out, e.g. computer stations where there was only just room for the keyboard. As Bennett (2006) suggests, it seemed to be important to have defined spaces that could be owned:

The zigzag tables in the IC, the ones where you are not entirely sure how much space is yours. That really gets to me, I am like am I using your space? ...I like to know what is mine

Participants also commented on the resources they needed: food and drink, power sockets, and computers. Students often brought food with them for a long study session.

[My] laptop is not light and also I bring foods, water, books and modules. So many stuff, so I have to guarantee myself not starving from being here, so I bring coffee and water.

We are not allowed to eat here on 1st floor. But I bring foods with me, because I cannot bring food in the middle of the night."

"I have seen students carrying small kettles.

A few people felt it was useful to sit near book stock. But in general people withdrew the books they wanted. Immediate access to books was not a major factor in where they went to study. Books could be seen more as symbolic of a library, with all its associations, rather than actually directly used resource.

Help from other students was mentioned more than help from support staff or academic staff. This was consistent with the sense the library staff had that students had a need for help, but did not realise librarians were the people to help them. If staff were mentioned, it was more around the creation of a safe and orderly working environment, than specific study advice. Working close to academic staff was rarely mentioned as desirable.

Thus the library spaces were attractive when they offered suitable sensory possibilities for the task in hand; a particular set of social resources; and the opportunity to take ownership, spread out and organise a comfortable environment around one.

\section{Discussion: informal learning spaces as destinations}

Confirming previous research, the study found that the libraries and the Diamond learning spaces at the University of Sheffield were important places where students learned. Students did not work 
much off campus (except at home). Rather, they explored university spaces and identified favourite places to work. The quality of being "library", understood as an adjective, to some extent symbolised by books on shelves (not in themselves necessarily an important resource) was an important marker of a quiet, safe and comfortable place to work. Seeing others working helped discipline oneself to work. Working alongside others one knew was also important for companionship rather than working directly on the same task. Thus informal learning spaces in the libraries and Diamond, where students worked for long periods alongside friends, were a home base on campus, perhaps more than academic departmental buildings.

The importance of the sensory aspect of this learning landscape, reminds us that the body is central to learning. It does not seem convincing to see learning as simply about quieting the body so that the mind can think, in some Cartesian dualism. Rather it appears that informal learning is experienced as embodied. A visual and scopic order was often mentioned by students as important to where they studied, so too are different regimes of noise and sound. There were also suggestions of the role of other senses such as of temperature and movement. This somatic work (Vannini et al. 2012) is not passive and created by a pregiven environment; rather it is actively constructed by action and meaning making. Different types of informal learning were best done where there were particular sensory possibilities. It follows that the characteristics of the physical spaces used for informal study are important; they can affect what types of learning are carried through. This aligns with studies of basic learning activities such as reading and writing that increasingly stress its embodied nature (Mangen 2014; McLaughlin 2015; Clughen 2014). Choices of who to work alongside and whether others were visible and what they were doing, were also important.

Both Bennett and Gayle seem to be right: learning is social and therefore there is a value to informal spaces capable of "domestication", yet there is also value in the quiet communal feeling in a library. However, there was also a form of intense, pressured silence that students sought out when there was a very strict deadline approaching. This has a quite different feel from the quiet studious mood conjured up by Gayle. Thus "informal learning" is made up of a mix of a range of activities: intense revision, reading, quiet consultations with others, group work and socialising. Different learning tasks ideally required a particular sensory landscapeor sensescape - of light quality, what was visible and how oneself was visible, and a particular soundscape. Students recognised different temperature, air quality, cleanliness in different locations and variations at different times of day. These findings reflect that space is important to learning. The learning atmosphere or atmospheres, to adapt Sequeiros' (2011) phrase, seems to be constructed partly through the underlying architecture, partly by furnishing and layouts, but also actively by the students occupying the space themselves.

Although a planned environment, given student explorations through complex spaces like the Diamond and across different informal (and formal) learning spaces around the campus as a whole, we have to take seriously the way that students individually and collectively construct the meaning of these spaces. The walk with method is one of a number of qualitative methods that can help create data to reveal these experiences. Yet there is scope to go much further in mapping different sight and soundscapes around campus, and thinking about how the different senses are engaged in different types of informal learning task.

\section{Conclusion}

An important aspect of university education is learning how to learn. Finding the right types of space in which to undertake the different activities involved in learning is important. In this 
context learning is much less about what goes on in lecture theatres or seminar rooms, under the gaze of an academic, than is often assumed. Informal learning spaces seem to be increasingly important, because of trends in pedagogy, learners' demands for independence, spending on building driven by competition for students, easy access to rich digital resources and the professional drivers for librarians to find the best way they can contribute to the institution.

The contribution of the paper has been to identify the value to higher education theory and practice of work published in the library field in the specific area of "informal learning". This begins to fill one small gap in the general neglect of space and place in studies of education. The paper also reports an empirical study of student experience in one particular institution, based on a substantial body of data. The findings are significant for Higher Education teaching practice. The paper brings to the foreground the rich sensory experience of informal learning, in terms of light, visibility, and sound, but also temperature and movement etc. Different informal learning activities have different qualities as embodied experiences. Learning is social: but not just through group work, it is about finding companionship to support individual study. Users are active in constructing learning atmospheres. Such atmospheres arise from architecture, furnishing, signage and social convention. Spaces are designed and managed by professionals like architects and librarians, but critically the different atmospheres within which informal learning occurs are also actively created by users through their choices and somatic work. The library has to be understood as a key place where learning happens and the idea of libraryness is important to the creation of such rich learning environments. This becomes highly relevant as the campus is reconceptualised as a learning landscape, when library-like informal learning spaces may be created all across the campus. Further research is needed to build up a picture of the sensory landscapes on campuses, and how these shape learning experiences. A productive approach would be greater use of sensory methods (Pink 2015). Methodologically, the study employed the walk along interview method for the first time in this context. This could be extended to focus specifically on sensory experience (Wilson 2016). At the same time, we also need to unravel how experiences of physical space are interconnected with the digital side of learning.

At a practical level, it is important for educators to recognise the importance of where students actually learn. Learning is not all going on purely in the classroom or even online. As teachers, we need to think more about the spatial demands of independent and especially group learning, e.g. when setting up group work. New spaces for learning in departments must accommodate a variety of activities. In this context, there is a need to be alert to the hidden curriculum aspect of space, the cultural messages unintentionally conveyed by how space is used that can have the effect of creating inequalities in access to learning (Costello 2000). On a pragmatic managerial level, the pressure on space particularly at examination time, suggests value in flexibility, e.g. in assessment periods there are fewer lectures taking place, but the study spaces become packed. Designing lecture theatres that could be repurposed for informal learning would be of value.

Compliance with ethical standards The research was approved by the University's ethics process.

Open Access This article is distributed under the terms of the Creative Commons Attribution 4.0 International License (http://creativecommons.org/licenses/by/4.0/), which permits unrestricted use, distribution, and reproduction in any medium, provided you give appropriate credit to the original author(s) and the source, provide a link to the Creative Commons license, and indicate if changes were made. 


\section{References}

Bennett, S. (2005). Righting the balance. In G. T. Freeman, S. Bennett, S. Demas, B. Frischer, C. A. Peterson, \& K. B. Oliver (Eds.), Library as place: Rethinking roles, rethinking space. Washington, DC: Council on Library and Information Resources https://www.clir.org/pubs/reports/pub129/bennett.html.

Bennett, S. (2006). The choice for learning. The Journal of Academic Librarianship, 32(1), 3-13. https://doi. org/10.1016/j.acalib.2005.10.013.

Bennett, S. (2011). Learning behaviors and learning spaces. portal: Library and the academy, 11(3), 765-789. https://doi.org/10.1353/pla.2011.0033.

Bresler, L. (Ed.). (2013). Knowing bodies, moving minds: towards embodied teaching and learning. London: Kluwer.

Bryant, J., Matthews, G., \& Walton, G. (2009). Academic libraries and social and learning space: a case study of Loughborough University Library, UK. Journal of Librarianship and Information Science, 41(1), 7-18. https://doi.org/10.1177/0961000608099895.

Carpiano, R. M. (2009). Come take a walk with me: The "go-along" interview as a novel method for studying the implications of place for health and well-being. Health \& Place, 15(1), 263-272. https://doi.org/10.1016/j. healthplace.2008.05.003.

Cha, S. H., \& Kim, T. W. (2015). What matters for Students' use of physical library space? The Journal of Academic Librarianship, 41(3), 274-279. https://doi.org/10.1016/j.acalib.2015.03.014.

Clark, A. and Emmel, N. (2010). Using walking interviews. Realities Toolkit 13. ESRC National Centre for Research Methods. https://eprints.ncrm.ac.uk/1323/1/13-toolkit-walking-interviews.pdf.

Clughen, L. (2014). 'Embodied writing support': The importance of the body in engaging students with writing. Journal of Writing in Creative Practice, 7(2), 283-300. https://doi.org/10.1386/jwcp.7.2.283_1.

Costello, C. Y. (2000). Schooled in the classroom. In E. Margolis (Ed.), The hidden curriculum in higher education (pp. 43-60). London: Routledge.

Cox, A. M. (2011). Students' experience of university space: an exploratory study. International Journal of Teaching and Learning in Higher Education, 23(2), 197-207.

Crook, C., \& Mitchell, G. (2012). Ambience in social learning: Student engagement with new designs for learning spaces. Cambridge Journal of Education, 42(2), 121-139. https://doi.org/10.1080/0305764 X.2012.676627.

Dubé, T. V., Schinke, R. J., Strasser, R., \& Lightfoot, N. (2014). Interviewing in situ: employing the guided walk as a dynamic form of qualitative inquiry. Medical Education, 48(11), 1092-1100. https://doi.org/10.1111 /medu.12532.

Dugdale, S. (2009). Space strategies for the new learning landscape. Educause Review, 44(2), 51-62.

Ellis, R. A., \& Goodyear, P. (2016). Models of learning space: integrating research on space, place and learning in higher education. Review of Education, 4(2), 149-191. https://doi.org/10.1002/rev3.3056.

Evans, J., \& Jones, P. (2011). The walking interview: methodology, mobility and place. Applied Geography, 31(2), 849-858. https://doi.org/10.1016/j.apgeog.2010.09.005.

Gayton, J. T. (2008). “Academic libraries: 'social' or 'communal?"” The nature and future of academic libraries. The Journal of Academic Librarianship, 34(1), 60-66. https://doi.org/10.1016/j.acalib.2007.11.011.

Harrop, D., \& Turpin, B. (2013). A study exploring learners' informal learning space behaviors, attitudes, and preferences. New Review of Academic Librarianship, 19(1), 58-77. https://doi.org/10.1080 /13614533.2013.740961.

Holton, M., \& Riley, M. (2014). Talking on the move: place-based interviewing with undergraduate students. Area, 46(1), 59-65. https://doi.org/10.1111/area.12070.

Hopwood, N., \& Paulson, J. (2012). Bodies in narratives of doctoral students' learning and experience. Studies in Higher Education, 37(6), 667-681. https://doi.org/10.1080/03075079.2010.537320.

Howes, D. and Classen, C. (2013). Ways of Sensing: Understanding the Senses in Society, Routledge.

Hunter, J., \& Cox, A. (2014). Learning over tea! Studying in informal learning spaces. New Library World, 115(1/2), 34-50. https://doi.org/10.1108/NLW-08-2013-0063.

Jamieson, P. (2009). The serious matter of informal learning. Planning for Higher Education, 37(2), 18-25.

Jamieson, P. (2013). Reimagining space for learning in the university library. In M. Graham \& G. Walton (Eds.), University libraries and space in the digital world (pp. 141-154). London: Routledge.

Jones, P., Bunce, G., Evans, J., Gibbs, H., \& Hein, J. R. (2008). Exploring space and place with walking interviews. Journal of Research Practice, 4(2) http://jrp.icaap.org/index.php/jrp/article/viewArticle/150.

Kusenbach, M. (2003). Street phenomenology the go-along as ethnographic research tool. Ethnography, 4(3), 455-485. https://doi.org/10.1177/146613810343007.

Lewis, M. (2010). The University of Sheffield library information commons: a case study. Journal of Library Administration, 50(2), 161-178. https://doi.org/10.1080/01930820903455040. 
Mangen, A. (2014). The digitisation of narrative reading: theoretical considerations and empirical evidence. In J. Kircz \& A. van der Weel (Eds.), The unbound book (pp. 91-106). Amsterdam: Amsterdam University Press.

Mattern, S. (2007). Resonant texts: Sounds of the American public library. The Senses and Society, 2(3), 277302. https://doi.org/10.2752/174589307X233521.

Matthews, K. E., Andrews, V., \& Adams, P. (2011). Social learning spaces and student engagement. Higher Education Research \& Development, 30(2), 105-120. https://doi.org/10.1080/07294360.2010.512629.

May, F., \& Swabey, A. (2015). Using and experiencing the academic library: a multi-site observational study of space and place. College \& Research Libraries, 76(6), 771-795. https://doi.org/10.5860/crl.76.6.771.

McLaughlin, T. (2015). Reading and the body. London: Palgrave, MacMillan.

O'Connor, E. (2007). Embodied knowledge in glassblowing: the experience of meaning and the struggle towards proficiency. The Sociological Review, 55(s1), 126-141. https://doi.org/10.1111/j.1467-954X.2007.00697.x.

O'Connor, L. (2009). Information literacy as professional legitimation: the quest for professional jurisdiction. Library Review, 58(4), 272-289. https://doi.org/10.1108/00242530910978190.

Ojennus, P., \& Watts, K. A. (2015). User preferences and library space at Whitworth University Library. Journal of Librarianship and Information Science EarlyCite. https://doi.org/10.1177/0961000615592947.

Pink, S. (2015). Doing sensory ethnography (2nd ed.). London: Sage.

Sequeiros, P. (2011). The social weaving of a reading atmosphere. Journal of Librarianship and Information Science, 43(4), 261-270. https://doi.org/10.1177/0961000611425823.

Temple, P. (2008). Learning spaces in higher education: an under-researched topic. London Review of Education, 6(3), 229-241. https://doi.org/10.1080/14748460802489363.

University of Sheffield. (2017). Spaces in the Diamond, https://www.sheffield.ac.uk/diamond/spaces

Vannini, P., Waskul, D., \& Gottschalk, S. (2012). The senses in self, society and culture. London: Routledge.

Wilson, H. F. (2016). Sonic geographies, soundwalks and more-than-representational methods. In M. Bull \& L. Back (Eds.), The auditory culture reader (2nd ed., pp. 163-172). London: Bloomsbury.

Yelinek, K., \& Bressler, D. (2013). The perfect storm: a review of the literature on increased noise levels in academic libraries. College \& Undergraduate Libraries, 20(1), 40-51. https://doi.org/10.1080 $/ 10691316.2013 .761095$.

Yoo-Lee, E., Heon Lee, T., \& Velez, L. (2013). Planning library spaces and services for Millennials: an evidencebased approach. Library Management, 34(6/7), 498-511. https://doi.org/10.1108/LM-08-2012-0049. 